\title{
The Chemistry of the Sesquiterpene Alkaloids
}

\author{
Timothy J. Brocksom, * Kleber T. de Oliveira and André L. Desiderá \\ Laboratório de Química Bioorgânica, Departamento de Química, Universidade Federal de São Carlos (UFSCar), \\ Rod. Washington Luís km 235, 13565-905 São Carlos-SP, Brazil
}

\begin{abstract}
We present the occurrence, structures, biological activities, biosynthesis, and syntheses of the sesquiterpene alkaloids.
\end{abstract}

Keywords: terpenes, biosynthesis, sesquiterpenoid alkaloids, isolation, synthesis

\section{Introduction}

Natural products (NPs; also called secondary metabolites) have fascinated mankind for several thousand years due to their useful properties and easy isolation. ${ }^{1}$ They have long been used in medicine, personal care, food preparation, and even as poisons. Their study is routine in several sciences including chemistry, pharmacy, botany and biology. This importance and interest has resulted in several relevant textbooks. ${ }^{1}$ An important theory dealing with the existence of NPs has been introduced by Schreiber ${ }^{2}$ on their evolution; this idea proposes that NPs are created for their relevance to the host species, and can then remain if useful, become extinct if not, or suffer modifications to create new NPs, as the host sees fit.

Of the estimated 300 thousand known NPs some 80 thousand are terpenoids. ${ }^{3}$ The terpenoids are a homogeneous group of molecules, as they can easily be identified and classified due to the number and arrangement of the carbon atom skeletons; into monoterpenes (10 carbon atoms), sesquiterpenes (15 carbon atoms), diterpenes (20 carbon atoms), sesterterpenes ( 25 carbon atoms) and triterpenes (30 carbon atoms). The steroids are metabolic derivatives of the triterpenes, and there are several higher terpenes with further multiples of five carbon atoms, leading up to the polymer rubber. Obviously, this also permits the existence of metabolically modified terpenoid structures with more (homo-) or less (nor-) carbon atoms than the above numbers. The homogeneity of the terpenoids is due to a very unified biosynthesis, which involves the

*e-mail: brocksom@terra.com.br

In memoriam: Ângelo da Cunha Pinto - our friend, scientific ally and constant teacher. combination of isoprene (5 carbon atoms) precursors, and is illustrated in Scheme 1.

This simplified version starts with the two basic isoprenoid units, dimethylallylpyrophosphate (DMAPP) and isopentenylpyrophosphate (IPP), produced either by the mevalonate or the deoxyxylulose (methyl erythritol) routes. Then, synthase enzymes join these isoprenoid units into geranyl (C-10), farnesyl (C-15), geranyl-geranyl (C-20), geranyl-farnesyl (C-25) and bis-farnesyl (C-30) linear intermediates. These relatively simple molecules cyclise into the immensely diverse range of (poly)cyclic structures when the cyclase enzymes take over. Finally, oxidase enzymes transform these (poly)cyclic hydrocarbons into the individual examples of the final NPs. These processes are exemplified in Scheme 2. This magnificent and highly organised biosynthesis is also notable for the very economical use of starting materials, intermediates, and chemical reactions; the envy of synthetic organic chemists.

Terpenoids also take part in mixed biosynthetic processes joining with NPs from other origins (meroterpenoids), ${ }^{4}$ or by uniting with other terpenoids (oligoterpenoids), ${ }^{5}$ and by including atoms not usual to their normal biosynthesis. The tremendous structural variation of terpenoids (and NPs) can easily be verified by reading the "Hot off the Press" articles published bimonthly in Natural Product Reports. Examples of the first two types of NPs are shown in Figure 1.

Terpenoids can also include nitrogen atoms and therefore become alkaloids, as can be seen in the following examples (Figure 2).

The sesquiterpenoids (C-15) form an immense group of NPs with extraordinary structural variety, and Dickschat and co-workers ${ }^{3}$ have listed 121 different (poly)cyclic 

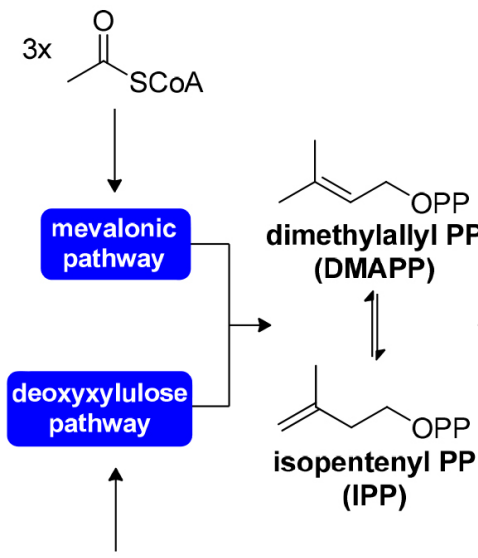
dimethylallyl PP (DMAPP)

$\overbrace{\mathrm{OH}}^{\mathrm{OHC}} \mathrm{OPP}$

$+$

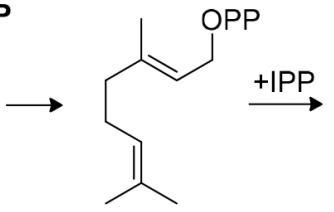<smiles>CC(C)=CCCC(C)=CCCC(C)=CCOP</smiles><smiles>CC(P)C(C)[PbH]</smiles>
isopentenyl PP (IPP) geranyl PP

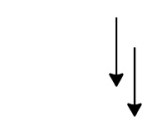
farnesyl PP geranyl-geranyl (FPP)
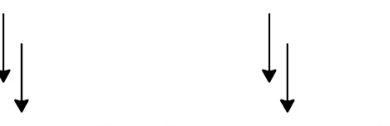
pyrophosphate

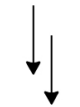<smiles>CC(=O)C(=O)O</smiles>

Scheme 1. General scheme for the biosynthesis of terpenoids.<smiles>CC(C)=CCC/C(C)=C/CO[PH+]</smiles>

geranyl PP<smiles>CC(C)=CCCC=C(C)CCC=C(C)C</smiles>

farnesyl PP<smiles>CC(C)=CCCC(C)=CCCC(C)=CCCC(=O)O</smiles>

geranylgeranyl PP

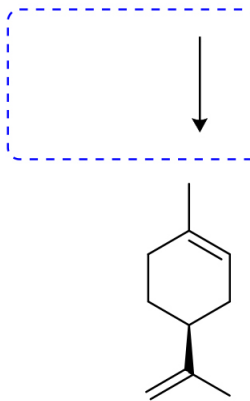

limonene

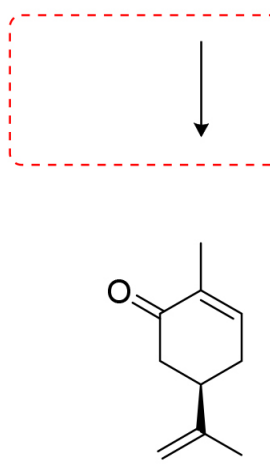

guaiane
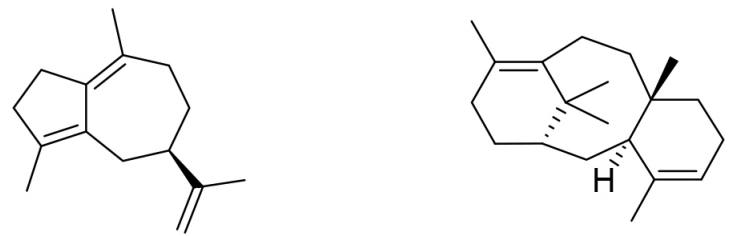

taxadiene

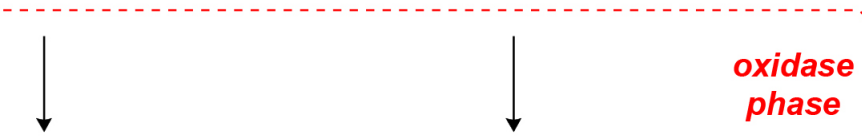

carvone

guaianolide

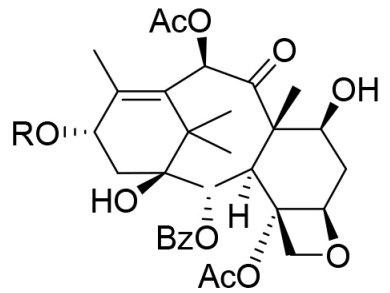

paclitaxel 


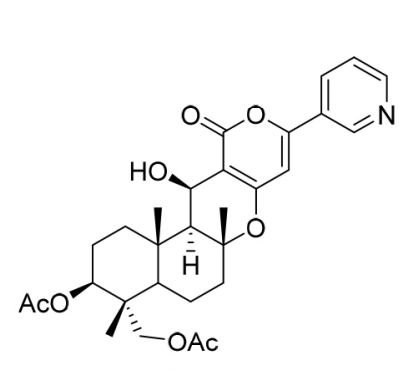

pyripyropene<smiles>CC1=CCC[C@]2(C)[C@H](C)[C@H](C)CC[C@]12CC1=C(O)C(=O)C(NCC(=O)O)=CC1=O</smiles>

nakijiquinone $A$

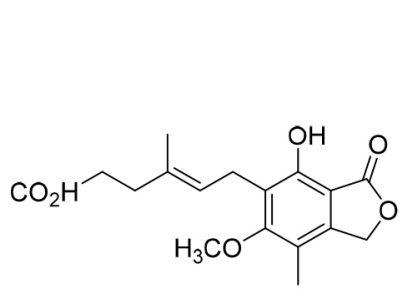

mycophenolic acid<smiles>C[C@H]1CC[C@]2(C)C(C)(C)CCC[C@]2(C)c2c1oc1cc(O)c(O)c(C=O)c21</smiles>

liphagal

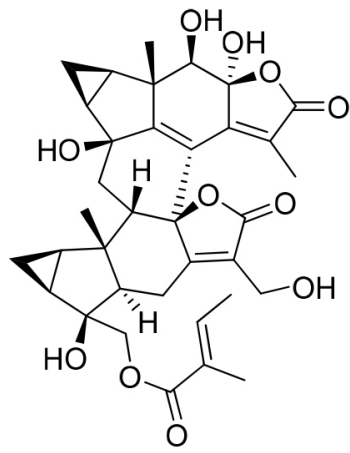

heriols B<smiles>CC1=CCC(/C(C)=C/[C@@H]2C=C(C)CC[C@]2(C)/C=C/C=C(\C)[C@H]2CC=C(C)CC2)CC1</smiles>

bis-bisabolene skeleton<smiles>COc1cc2c(c3c1[C@@H](C)CC[C@H]3C(C)C)O[C@H]1C(=O)C3=C(C(=O)[C@]1(C)C2)[C@@H](C(C)C)CC[C@H]3C</smiles>

bisdioxycalamenene

Figure 1. Examples of meroterpenoids and bis-terpenoids.

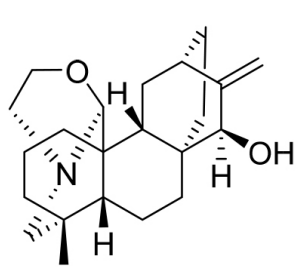

atisine

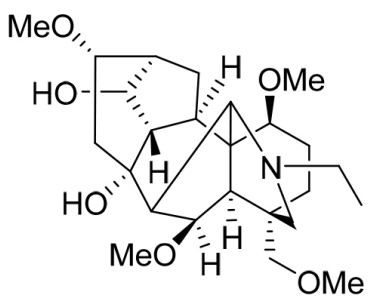

chasmanine

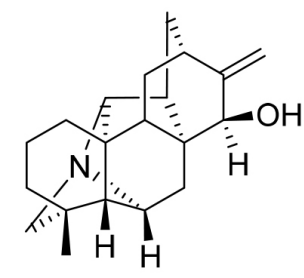

nominine

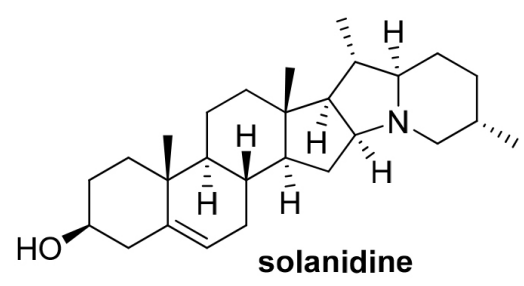

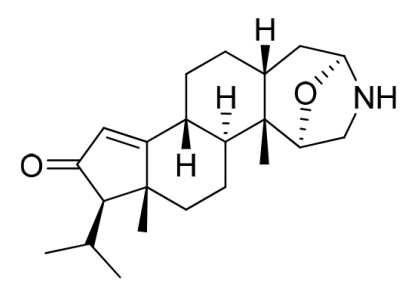

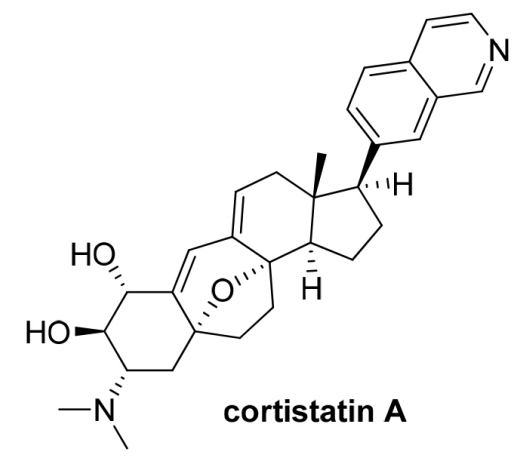

samandenone

Figure 2. Diterpene and triterpene alkaloids. 
carbon skeletons available from farnesyl pyrophosphate. This publication also determines the number of ring sizes (from 3 to 11) present in the cyclic carbon skeletons, with an obvious prevalence for five and six membered-rings.

In this review we will describe the chemistry of the sesquiterpene alkaloids, a specific group of NPs derived from sesquiterpenes with the inclusion of a nitrogen atom within the basic carbon skeleton of the sesquiterpenoid structure. NPs with extraneous nitrogen atoms remote from the sesquiterpene skeleton are not included. ${ }^{6}$ To clarify this point, the NPs exemplified in Figure 3 are not discussed here, as the nitrogen atom is not part of the sesquiterpenoid nucleus, and is therefore derived from a separate biosynthesis. ${ }^{6}$

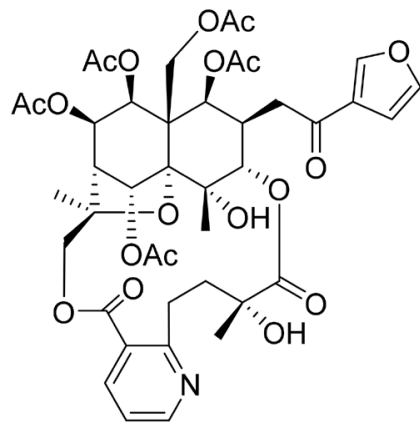

wilfortrine

Figure 3. An example of sesquiterpenoids with extraneous nitrogen atoms.

\section{The Sesquiterpenoid Alkaloids}

The great majority of the sesquiterpene alkaloids belong to two major groups; the dendrobines and the guaipyridines, as shown in Scheme 3 with a biogenetic proposal.

\section{The Dendrobine Sesquiterpenoid Alkaloids}

The NP dendrobine was first isolated in $1932,{ }^{7}$ and its structure defined in the $1960 \mathrm{~s},{ }^{8}$ being re-isolated several times together with other highly related compounds (Figure 4). ${ }^{9}$ Dendrobine is part of the traditional Chinese herbal medicinals, ${ }^{10}$ and is used as a general tonic, including use for improving the vocal chords. Further biological tests have shown rather limited activities, allied to a certain toxicity, which obviously has reduced interest in this aspect of their chemistry. Other dendrobine derivatives are also presented in Figure 4.

The biogenesis is presented in Scheme 3, and based upon labelling experiments suggests a common pathway to the picrotoxane sesquiterpenes and then the dendrobine alkaloids (Scheme 4). ${ }^{11}$

The highly condensed 5,5,6 tricyclic skeleton containing the nitrogen atom, a bridged lactone, and six stereogenic centres around the cyclohexane ring (seven contiguous), make these molecules exciting synthetic challenges. The biological activities perhaps do not justify this interest, but the molecular architecture explains so many publications from eminent groups. Most of these publications are directed to the successful demonstration of important new synthetic methodologies for the construction of highly condensed polycyclic frameworks. In other words, the dendrobine molecule is a perfect target for exploring new strategies and tactics in organic synthesis.

\section{Synthesis of Dendrobine Sesquiterpene Alkaloids}

We have selected some of the many syntheses that have

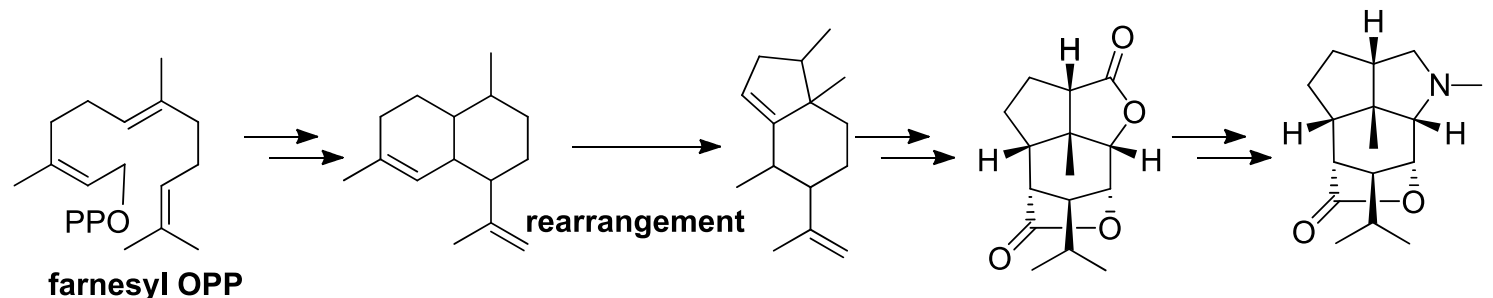

farnesyl OPP

(-)-dendrobine

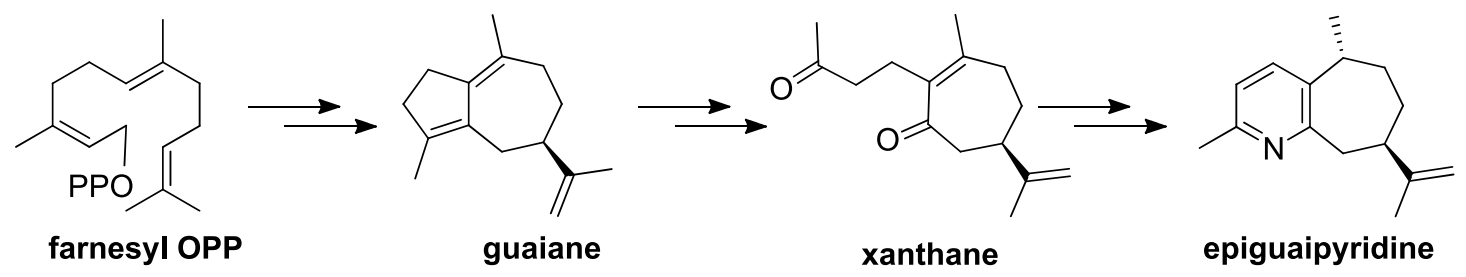

Scheme 3. The dendrobine and guaipyridine type sesquiterpene alkaloids, with biogenetic proposals. 


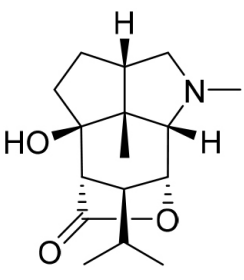

dendramine

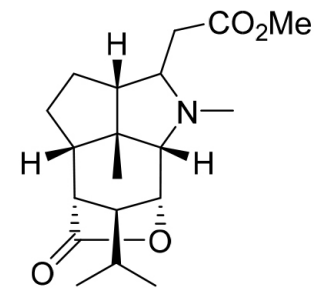

dendrine

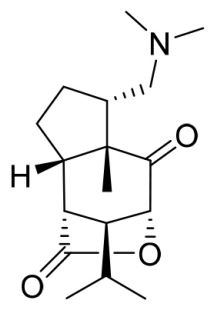

nobilonine

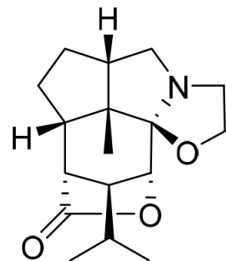

dendroxine

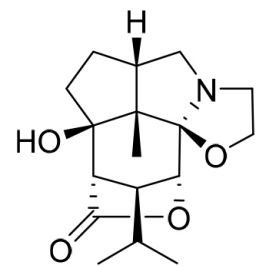

hydroxydendroxine

Figure 4. The dendrobine family of sesquiterpenoid alkaloid NPs.

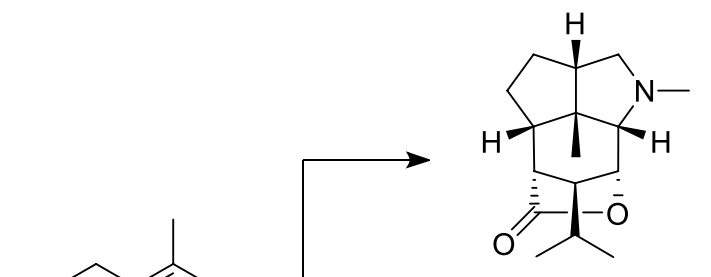

(-)-dendrobine
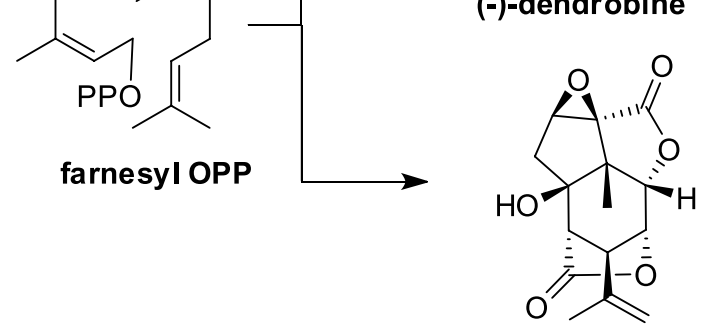

picrotoxinin

Scheme 4. The dendrobine alkaloids and the picrotoxane sesquiterpenes.

been published over the last forty years, not necessarily in chronological order and which represent a personal choice.

This discussion starts with the most recent synthesis, performed by Kreis and Carreira, ${ }^{12}$ published in 2012,

where all relevant references to previous total and partial syntheses are included. The key step involves reaction of the pendant aldehyde with $\mathrm{N}$-methylbenzylamine to form the enamine, intramolecular Michael addition at the enone, and in situ reduction of the benzyl group. This domino sequence creates the cis-fused hydrindane system, now with the pendant $N$-methyl group ready to cyclise to the full tricyclic core structure (Scheme 5).

Kende et al. ${ }^{13}$ use a substituted para-benzoquinone plus butadiene Diels-Alder cycloadduct, which undergoes $\mathrm{C}=\mathrm{C}$ double bond cleavage and a directed intramolecular aldol reaction thus creating the $c i s$-hydrindane system. Reductive amination includes the nitrogen atom, and finalises the tricyclic framework (Scheme 6).

The Martin and $\mathrm{Li}^{14}$ synthesis involves the two starting materials forming a substrate for an intramolecular Diels-Alder (IMDA) reaction, thus generating the tricyclic framework in this key step (Scheme 7).

The Cassayre and Zard ${ }^{15}$ synthesis involves an intramolecular Pauson-Khand reaction (PKR) as the key step, thus forming directly the tricyclic system (Scheme 8).

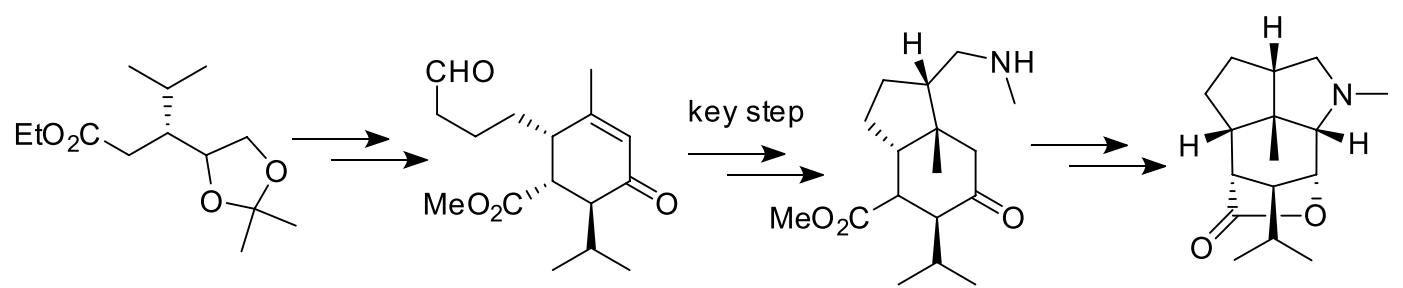

(-)-dend robine 


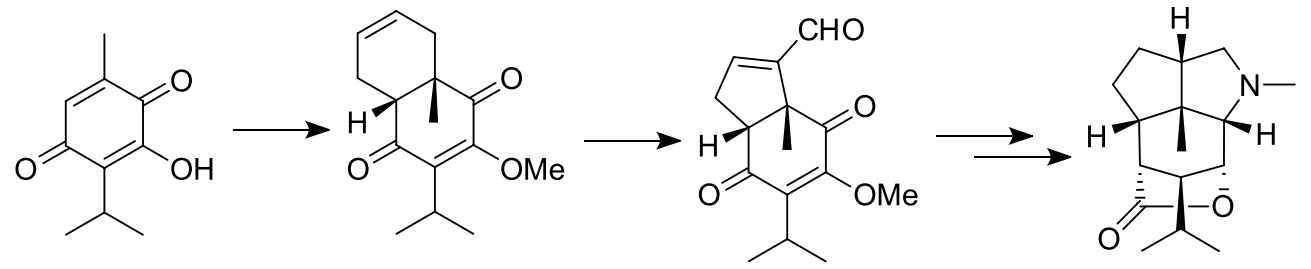

(-)-dendrobine

Scheme 6. The Kende synthesis of dendrobine. ${ }^{13}$<smiles>C=C(/C=C/N(C)C(=O)C1CCC=C1C)C(C)C(C)C(C)C</smiles>

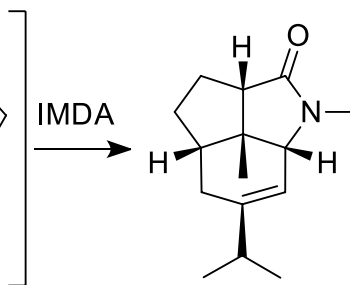

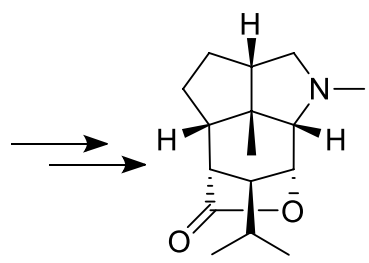

(-)-dendrobine

Scheme 7. The Martin-Li synthesis of dendrobine. ${ }^{14}$

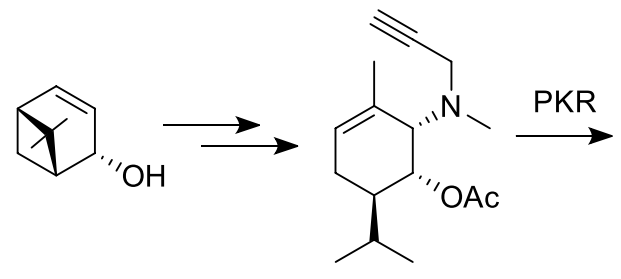

Scheme 8. The Cassayre-Zard synthesis of dendrobine. ${ }^{15}$

\section{The Guaipyridine Sesquiterpenoid Alkaloids}

The guaipyridine sesquiterpenoid alkaloids are NPs with relatively simple bicyclic (or at the most tricyclic) molecular architectures, with a seven-membered carbocyclic ring fused to the pyridine ring, and two stereogenic centres. ${ }^{16}$ The biogenesis is shown in Scheme 3, and goes from farnesyl pyrophosphate to the basic guaiane skeleton. Cleavage of a $\mathrm{C}=\mathrm{C}$ double bond at the bicycle junction produces the xanthane sesquiterpene skeleton, ${ }^{17}$ and inclusion of a nitrogen atom between the two carbonyl groups then finalises the sequence to the guaipyridine framework.

The Büchi laboratory demonstrated in 1966 the presence of two sesquiterpenoid alkaloids in the commercially important Patchouli essential oil, of which one was named patchoulipyridine and the other epiguaipyridine (Figure 5). ${ }^{18}$ The other guaipyridines that have been isolated are also shown in the same Figure 5 for comparison. ${ }^{19}$ These molecules present very limited biological activities, which has perhaps dampened interest in further prospection.

\section{Synthesis of Guaipyridine Sesquiterpene Alkaloids}

The relative simplicity of the structures has led to a more limited synthetic interest, perhaps directed initially to structure proof. The original Büchi laboratory publication of the two alkaloids (Figure 5) also introduced a synthesis of patchoulipyridine from $\beta$-patchoulene by reaction with hydrazoic acid (Scheme 9). ${ }^{18}$

The initial addition product with $\mathrm{HN}_{3}$ rearranges as indicated, and is then dehydrogenated (aromatised) to a mixture including patchoulipyridine as the major product, after chromatographic separation. The addition of $\mathrm{HN}_{3}$ to $\beta$-patchoulene is not regioselective, and the other possible addition leads to a minor isomeric pyridine product, as shown in Scheme 9.

Other syntheses have been disclosed as shown in Schemes 10 to 12 . Koyama et al. ${ }^{20}$ start with (+)-10-camphorsulfonic acid, take out the sulfonic acid residue, prepare the butenyloxime derivative, and thermolyse at $180{ }^{\circ} \mathrm{C}$ for 24 hours. From the complex reaction mixture, (-)-patchoulipyridine was isolated in $8 \%$ yield by preparative thin layer chromatography. 
<smiles>Cc1ccc2c(n1)CC1CCC2(C)C1(C)C</smiles>

patchoulipyridine<smiles>C=C(C)[C@@H]1CC[C@@H](C)c2ccc(C)nc2C1</smiles>

guaipyridine<smiles>C=C(C)[C@@H]1CC[C@@H](C)c2ccc(C)nc2C1</smiles>

epiguaipyridine<smiles>Cc1ccc2c(n1)C[C@@H](C(C)(C)O)CC[C@H]2C</smiles>

cananodine<smiles>C=C(C(=O)OCC)C1CC[C@@H](C)c2ccc(C)nc2C1</smiles>

rupestine $A$<smiles>COC(=O)C(C)[C@@H]1CC[C@@H](C)c2ccc(C)nc2C1</smiles>

rupestine $F$

Figure 5. The guaipyridine sesquiterpene alkaloids.<smiles>CC1CCC2=C1CC1CCC2(C)C1(C)C</smiles>

$\beta$-patchoulene

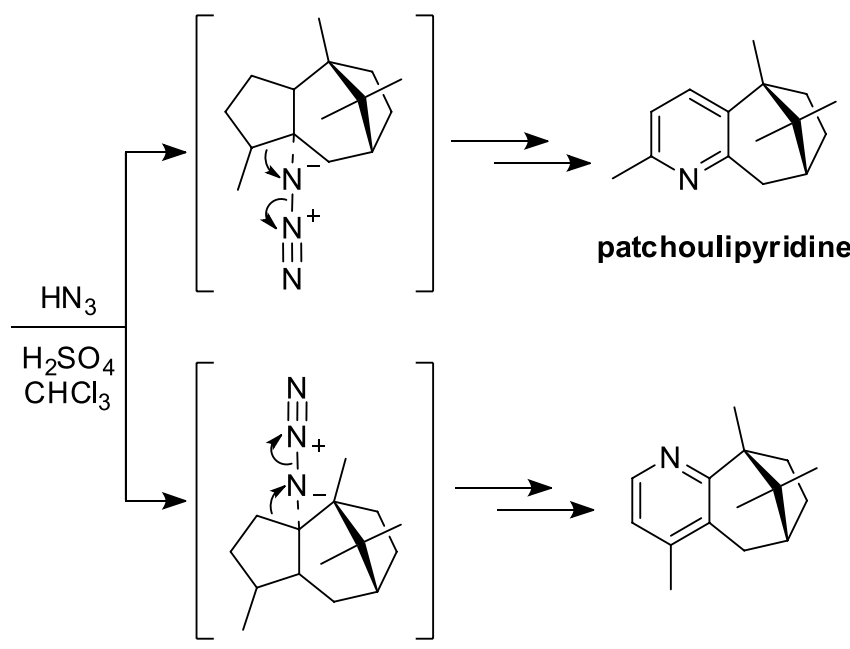

Scheme 9. The Büchi patchoulipyridine synthesis. ${ }^{18}$

Van der Gen et al. ${ }^{21}$ have disclosed two syntheses starting from different guaiane sesquiterpenes (Scheme 11), basically by double bond cleavage to xanthane carbon skeletons ${ }^{17}$ and nitrogen atom inclusion and cyclisation. ${ }^{21}$

Finally, Craig and Henry use enantiopure $R$-(-)-citronellene as the starting material, and after cleavage of the propylidene group and re-construction with a chiral auxiliary, allows a ring-closing metathesis (RCM) reaction to the cycloheptene ring. Cananodine is then synthesised by a simple sequence of reactions (Scheme 12).22

Our laboratory has investigated the guaipyridines, in a diversity oriented synthetic approach to several different sesquiterpene frameworks, based upon the large-scale availability of a chiral enantiopure cycloheptenone intermediate produced from naturally occurring $(R)-(-)$-carvone (Scheme 13). ${ }^{23}$ Alkylation of the cycloheptenone produces the xanthane sesquiterpene carbon skeleton, and then treatment with $\mathrm{NH}_{3}$ cyclises to guaipyridine. ${ }^{24}$

\section{The Rotundine Sesquiterpenoid Alkaloids}

Three quite different sesquiterpene alkaloids have been

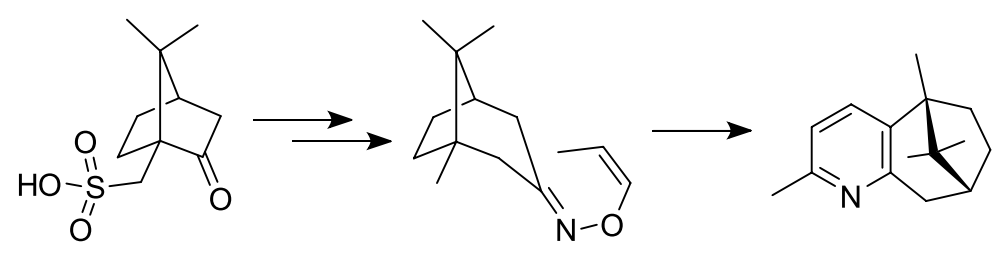

(+)-10-camphorsulfonic acid 
<smiles>CC1CCC(C(C)(C)O)CC2=C1CCC2C</smiles>

guaiol

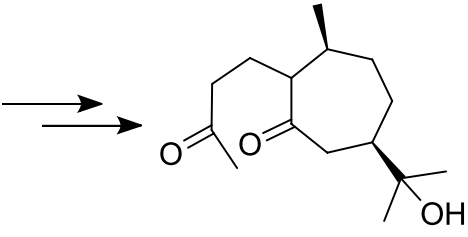

$\mathrm{OH}$<smiles>C=C(C)C1CCC(C)c2ccc(C)nc2C1</smiles>

guaipyridine<smiles>C=C(C)[C@@H]1CC[C@@H](C)c2ccc(C)nc2C1</smiles>

$\alpha$-gurjunene

epiguaipyridine

Scheme 11. The Van der Gen syntheses of guaipyridines. ${ }^{21}$

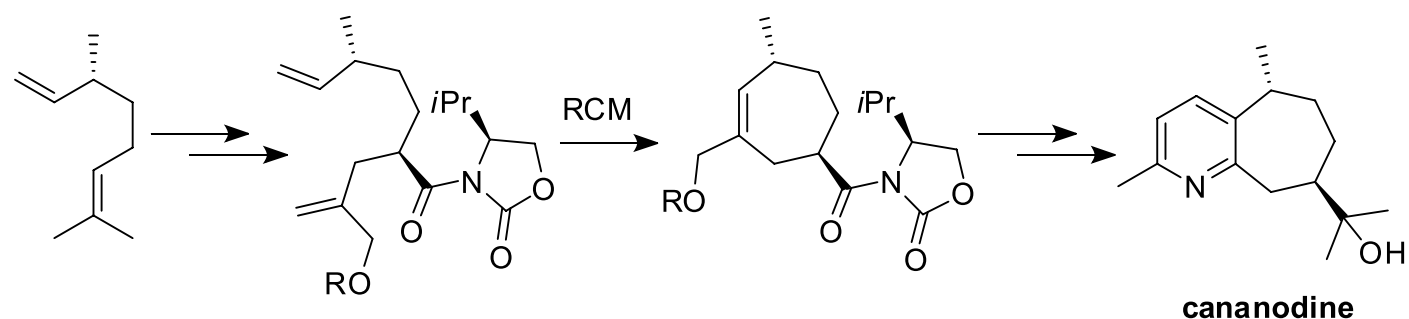

Scheme 12. The Craig-Henry synthesis of cananodine. ${ }^{22}$

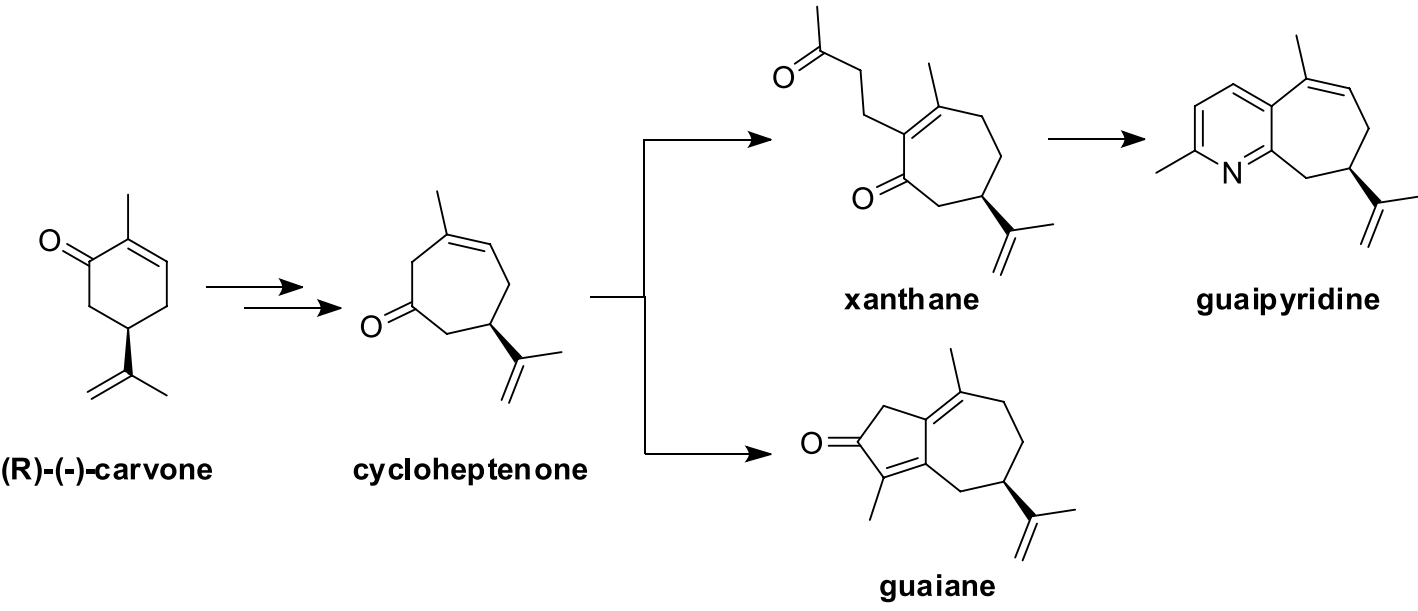

Scheme 13. Our synthetic approach to xanthane and guaiane sesquiterpenes, and guaipyridines.

isolated from Cyperus rotundus, and have been named as rotundines A, B and C. Their structures are presented in Figure $6 .{ }^{25}$

\section{Conclusion and Perspectives}

This relatively limited group of NPs clearly demonstrates the immense capacity of Nature to produce small molecules of evident interest to the host species. Their existence is a constant challenge to organic chemists, both in terms of isolation and structural identification and also synthesis.

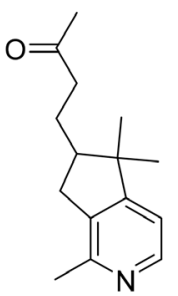

rotundine $A$

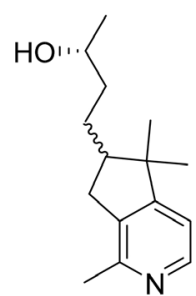

rotundine $B$<smiles>Cc1nccc2c1C[C@H](CCC(C)O)C2(C)C</smiles>

rotundine $\mathrm{C}$
Figure 6. The rotundine sesquiterpene alkaloids..$^{25}$ 


\section{Acknowledgments}

The authors wish to thank our past and present colleagues in the Bio-Organic Chemistry Lab. We acknowledge financial support and fellowships from FAPESP (2015/21110-4 and 2011/13993-2), CAPES and $\mathrm{CNPq}$. The $(R)-(-)$-carvone used in our research was kindly supplied by Firmenich SA.

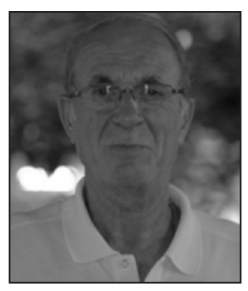

Timothy John Brocksom received his PhD in 1968 at Liverpool University, under the guidance of Prof Sir A. R. Battersby. He then moved to Stanford University for a postdoctoral position with Prof W. S. Johnson, and in 1970 on to the University of British Columbia for a second postdoctoral with Prof J. P. Kutney. In 1972 he came to the University of São Paulo as visiting Professor, and in 1977 to the Federal University in São Carlos as full Professor. His research interests are in bio-organic chemistry, and encompass methodologies and syntheses leading to bioactive terpenoids, with emphasis on polycylic skeleton construction employing the Diels-Alder reaction and transition metal catalyzed reactions.

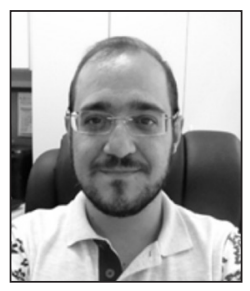

Kleber Thiago de Oliveira was awarded his PhD in Organic Chemistry in 2006 from the University of São Paulo (USP-RP, Ribeirão Preto), under the guidance of Prof Mauricio Constantino. He carried out postdoctorals, with Prof Cavaleiro at the University of Aveiro (2006-2007), with Prof Iamamoto at USP-RP (2008) and more recently with Prof D. T. McQuade at the Florida State University (2015). In 2009 he became a professor at the Federal University of $A B C$ and in 2010 moved to the Federal University of São Carlos. His research is focused on synthesis and applications of photosensitizers, natural products synthesis and continuous flow processes.

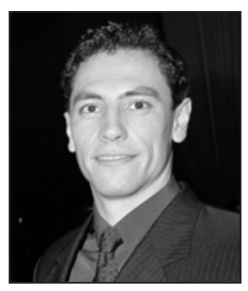

André Luiz Desiderá graduated in chemistry at the Federal University of Viçosa (2007) and completed his MSc (2012) and PhD degrees (2016) under the guidance of Prof Timothy J. Brocksom at the Federal University of São Carlos, with emphasis in organic synthesis of bioactive compounds derived from sesquiterpenes.

\section{References}

1. Hendrickson, J. B.; The Molecules of Nature; W. A. Benjamin: New York, USA, 1965; Geissman, T. A.; Crout, D. H. G.; Organic Chemistry of Secondary Plant Metabolism; Freeman, Cooper \& Company: San Francisco, USA, 1969; Mann, J.; Secondary Metabolism; Oxford University Press: Oxford, UK, 1978; Dewick, P. M.; Medicinal Natural Products: A Biosynthetic Approach, $3^{\text {rd }}$ ed.; John Wiley \& Sons: Chichester, UK, 2009.

2. Schreiber, S. L.; Bioorg. Med. Chem. 1998, 6, 1127.

3. Klapschinski, T. A.; Rabe, P.; Dickschat, J. S.; Angew. Chem. Int. Ed. 2016, 55, 10141.

4. Matsuda, Y.; Abe, I.; Nat. Prod. Rep. 2016, 33, 26.

5. Mao, S.-C.; Manzo, E.; Guo, Y.-W.; Gavagnin, M.; Mollo, E.; Ciavatta, M. L.; van Soest, R.; Cimino, G.; Tetrahedron 2007, 63, 11108; Li, C.-J.; Zhang, D.-M.; Luo, Y.-M.; Yu, S.-S.; Li, Y.; Lu, Y.; Phytochemistry 2008, 69, 2867.

6. Lião, L. M. In The Alkaloids: Chemistry and Biology, $1^{\text {st }}$ ed.; Cordell, G. A., ed.; Academic Press: San Diego, California, USA, 2003, vol. 60, p. 287; see also: Spivey, A. C.; Weston, M.; Woodhead, S.; Chem. Soc. Rev. 2002, 3, 43; Gao, J.-M.; Wu, W.-J.; Zhang, J.-W.; Konishi, Y.; Nat. Prod. Rep. 2007, 24, 1153.

7. Suzuki, H.; Keimatsu, I.; Ito, K.; J. Pharm. Soc. Jpn. 1932, 52, 1049; Suzuki, H.; Keimatsu, I.; Ito, K.; J. Pharm. Soc. Jpn. 1934, 54, 802.

8. Inubushi, Y.; Sasaki, Y.; Tsuda, Y.; Yasui, B.; Konika, T.; Matsumoto, J.; Katarao, E.; Nakano, J.; Tetrahedron 1964, 20, 2007; Inubushi, Y.; Sasaki, Y.; Tsuda, Y.; Nakano, J.; Tetrahedron Lett. 1965, 6, 1519.

9. Wang, H.; Zhao, T.; J. Nat. Prod. 1985, 48, 796; Inubushi, Y.; Tsuda, Y.; Katarao, E.; Chem. Pharm. Bull. 1966, 14, 668; Inubushi, Y.; Nakano, J.; Tetrahedron Lett. 1965, 31, 2723; Yamura, S.; Hirata, Y.; Tetrahedron Lett. 1964, 2, 79; Okamoto, T.; Natsume, M.; Onaka, T.; Uchimaru, F.; Shimizu, M.; Chem. Pharm. Bull. 1966, 14, 672.

10. Chen, K. K.; Chen, A. L.; J. Biol. Chem. 1935, 111, 653; Chen, K. K.; Chen, A. L.; J. Pharmacol. 1935, 55, 319.

11. Cordell, G. A.; Chem. Rev. 1976, 76, 425.

12. Kreis, L. M.; Carreira, E. M.; Angew. Chem. Int. Ed. 2012, 51, 3436.

13. Kende, A. S.; Bentley, T. J.; Mander, R. A.; Ridge, D.; J. Am. Chem. Soc. 1974, 96, 4332.

14. Martin, S. F.; Li, W. J.; J. Org. Chem. 1991, 56, 642.

15. Cassayre, J.; Zard, S. Z.; J. Am. Chem. Soc. 1999, 121, 6072.

16. Fraga, B. M.; Nat. Prod. Rep. 2012, 29, 1334; and subsequent annual reviews.

17. Vasas, A.; Hohmann, J.; Nat. Prod. Rep. 2011, 28, 824.

18. Büchi, G.; Goldman, I. M.; Mayo, D. W.; J. Am. Chem. Soc. 1966, $88,3109$. 
19. Su, Z.; Wu, H.-K.; He, F.; Slukhan, U.; Aisa, H. A.; Helv. Chim. Acta 2010, 93, 33; Su, Z.; Wu, H.; Yang, Y.; Aisa, H. A.; Slukhan, U.; Aripova, S.; J. Sep. Sci. 2008, 31, 2161; He, F.; Nugroho, A. E.; Wong, C. P.; Hirasawa, Y.; Shirota, O.; Chem. Pharm. Bull. 2012, 60, 213.

20. Koyama, J.; Okatani, T.; Ogura, T.; Tagahara, K.; Irie, H.; Chem. Pharm. Bull. 1991, 39, 481.

21. Van der Gen, A.; Van der Linde, L. M.; Witteveen, J. G.; Recl. Trav. Chim. Pays-Bas 1972, 91, 1433.

22. Craig, D.; Henry, G. D.; Eur. J. Org. Chem. 2006, 3558.
23. Alves, L. C.; Desiderá, A. L.; Oliveira, K. T.; Newton, S.; Ley, S. V.; Brocksom, T. J.; Org. Biomol. Chem. 2015, 13, 7633.

24. Brocksom, T. J.; Brocksom, U.; Frederico, D.; Tetrahedron Lett. 2004, 45, 9289.

25. Jeong, S.-J.; Miyamoto, T.; Inagaki, M.; Kim, Y.-C.; Higuchi, R.; J. Nat. Prod. 2000, 63, 673.

Submitted: January 4, 2017 Published online: March 14, 2017 